\title{
A STUDY OF THE CAUSATION OF INEBRIETY.
}

\author{
BY T. D. CROTHERS, M.D.,
}

SUPT. WALNUT LODGE, HARTFORD, CONN.

$\prod \begin{gathered}\mathrm{HE} \text { laws controlling inebriety have not yet emerged } \\ \text { from the superstition of vice and sin. }\end{gathered}$

The student of the next century will be amazed to find in this age of inquiry, that the study of inebriety was left almost entirely into the hands of clergymen and inebriates themselves. A few pioneers here and there are urging the profession to take up this subject, and pointing out the wide expanse of unexplored lands, full of mystery that will be found under the domain of law, rich in physiological fact and principle. The time has come for an accurate study of this subject above the levels of off-repeated opinions, that have never been based on any accurate observation from the first. The ordinary observer, reasoning from the fact that he is able to use or abstain from the use of spirits, concludes that all persons have the same power. The mental processes which precede or accompany the act of taking spirits are supposed to be the same in all cases.

When the act is often repeated, the patient is called an inebriate. All symptoms of disease are accidental, and growing out of the toxic action of alcohol. The remedy of course is to stop, and the process is to determine to do so, from fear of both physical and eternal death. Upon this theory a vast army of reformers have studied the subject 
for the purpose of showing the danger of inebriety, and the possibilities of stopping at the will of the patient. A careful clinical study of inebriety from a scientific point of view, not only disproves this theory, but reveals a complex and variable chain of causation, which moves on progressively from stage to stage. The supposed cause, alcohol, is seen to be only a symptom; and the apparent accidental use of spirits in the beginning is in many cases a psychical and pathological change. The failure of the patient to stop the use of spirits, although he desires to do so, is a strong hint of nerve degeneration. The strange psychical obtuseness of the mind to realize the results from the use of spirits, associated with all his usual sagacity on other topics, points out clearly a twilight approach of grave disease. Farther on in the case, the functional and organic disturbances appearing in many ways aptly justify the expression that inebriety is the very genius of destruction.

A comparison of the history of cases of this disorder reveals a regularity and certainty, in the progress from some definite cause, on to chronic stages and death. The conclusion that inebriety is a physical disease cannot be doubted.

Nearly every case of inebriety will be found in a person of previously defective organism.

This may be considered an established fact, in which the exceptional cases are not studied or understood. Hence, the first general study must include hereditary influence, and such other general conditions which unite in its growth.

A general outline of many of these facts may be of interest. No other disease is more certainly transmitted, not always directly in a craving for alcohol, but in nerve degenerations, which break out in this direction from the application of many exciting causes. A direct inheritance has been traced, in many cases, in children of inebriate 
parents, who manifested a craving for spirits from their earliest infancy.

It follows in collateral as well as direct lines of transmission, and leaves unmistakable marks of degeneration in the next generation.

The very poor, through the irregularities of living and hunger, with bad quality and conditions of food, develop perverted nutrition and low vitality, which is favorite soil for the propagation and transmission of inebriety. The very wealthy, from continuous stimulation and excess, with neglect of healthy activity of both body and mind, develop nutrient degenerations, both functional and organic, which appear in the next generation in inebriety and allied disorders.

Parents who are engaged in intense mental work and leading a sedentary life, such as literary men, clergymen, bankers, bookkeepers, inventors, etc., have often inebriate descendants. Many curious facts have been detailed relating to the physical condition of parents at the time of procreation, which have undoubtedly caused inebriety in the offspring; in one instance, related by the late Dr. Alvoid, of London, in which the children of a retailer of spirits born in this business were inebriates and dissolute, while those born after he had left the business were temperate and respectable citizens. The doctor concludes that occupation and the condition of parents at the time of conception are often the cause of inebriety. In many cases where inebriety has developed without any special chain of exciting causes, the unstable mental organization of the parents will account for it. They are usually people with disordered emotional faculties and unbalanced nutritive functions, the latter manifested in capricious appetites and unusual tastes for food and fluids.

My studies have revealed many cases that were clearly 
marked as inebriate diathesis,-cases that might remain free from the use of alcohol during a lifetime, or develop inebriety at once from some unknown exciting cause. Such transmit to their children this tendency either intensified or more diluted and harmless. This diathesis can be seen in the practice of nearly every physician, and is frequently associated with general organic degeneration marked by anæmia, neuralgia, and functional disorders of stomach and head. The body and brain are frequently developed out of proportion, the functional activity is intense, and the mind is uncertain, changeable, and vain, of ten displaying the force of genius and the weakness of a child, also a peculiar tendency to exhaustion. Such persons are often the visionary, unreal men whose credulity leads them into every new scheme of science and religion. Insanity, inebriety, and a large crop of varied nerve diseases are constantly springing out of this class. Not unfrequently they are fanatical, bigoted reformers in the temperance ranks, leading crusades against every form of evil, but in private life failing to sustain their public reputation. In this field a study of inebriety will point out the danger and give warning of the coming storm, which, if it does not break out in one generation, will in the next. Inebriety rarely comes on at once. The operative causes slumber along insidiously; then, from the application of some special conditions, burst out. Hence, inebriety is the culmination of long trains of degeneration which have gathered and coalesced from the past. These complex chains of causes, growing up in the past generation and handed down or developed in this generation have some special exciting cause. A study of these exciting causes will often throw great light on the nature and character of the case. The use of alcohol is only one of these factors, although it appears to be prominent in many cases. The physical condition at 
the time alcohol was first used to excess is frequently of great significance. For instance, when the person is suffering from great physical exhaustion, or any profound disturbance of the organism, the shock from the excess of alcohol is wide-reaching in its effects and influence. Many causes of inebriety have been traced to the ignorant efforts of friends to relieve conditions of physical exhaustion by alcohol as a medicine.

I am sustained in the view that inebriety comes frequently from injury of the brain or spinal cord. Such injuries may be obscure, but are always followed by neurasthenic states, and physical changes, with alteration of nutrition, for all of which alcohol is a pure sedative, and has the same apparent effect that food has in relieving the cravings of hunger. From these and other causes insanity or inebriety may come, depending on some unknown factor which determines the form of disease. Among the causes that are prominent may be mentioned blows on the head and injuries to the nerve trunks. A previously temperate man falls, striking on his head, or receives a blow which is soon forgotten. Soon he becomes a different man, and an inebriate without any reason or cause that can be seen by his friends. Injuries to the extremities react by some unknown law, in inebriety. A chaplain in the late war was injured in the leg, and drank spirits to intoxication for two years until the wound healed, then he recovered and was temperate ever after. A very temperate physician broke his arm and drank from this period on through life. A farmer became an inebriate from the time of amputation of a foot for frost-bite. Physical injuries that are recognized have frequently been found active causes of inebriety. Of these, railroad accidents, where the concussion and alarm are sudden, causing intense excitement and reaction, seem to be very prominent. A train on the Hud- 
son River Railroad jumped the rails and ran over the sleepers for some distance. The windows were broken and the lights went out. When the train stopped, a number of passengers were so paralyzed with fear that they could not walk. One continued his journey with difficulty, but began to drink from that time, and could not give any reason or cause for it, although suffering no apparent injury. A man who witnessed the blowing up of the steamer Adelphi in Norwalk, Conn., a few years ago, became profoundly excited, drinking to intoxication that night for the first time. From that moment he used alcohol constantly, and is now an inebriate. These instances are not uncommon, and may be found in the history of many cases. The same results follow prolonged exhaustion, loss of property, disappointment, grief, and occasional religious or political excitement. In one case a clergyman, after excessive labor in a revival, drank and became an inebriate. A merchant who lost his property drank at once to intoxication and never recovered. A lawyer became an inebriate from the death of his wife. A student failed to secure a prize and suffered from inebriety from this time.

The roll might be extended to almost every conceivable condition of exhaustion, either of the brain or body. Injury from temporary disease is often the starting-point of inebriety: as, for instance, a farmer in the harvest field drinking large quantities of ice-water, which produced a violent colic, for which alcohol was, used, reacting speedily into inebriety. A prominent lawyer, after prolonged overwork, suffered from fever and exhaustion, then, drank spirits, and later became an inebriate. Dyspepsia merges frequently into inebriety. Excessive hunger and thirst passes quickly into inebriety from some unknown causes. Practically, any disease which breaks up the nutritive function, causing different forms of perversions and changes, 
predisposes to inebriety in most cases. There is a field of causes which, in my opinion, will, when understood, explain much of the obscurity that now exists about the early stages of inebriety. It may be designated by the name of psychical traumatism. In general terms, this describes some obscure condition of degeneration and impairment of structure and function. The brain and nervous system has lost some power of restoration by which its integrity is preserved, and has taken on conditions favorable to the development of inebriety. This may be illustrated by the defective lung-power after an attack of pneumonia, or debility after a severe typhoid fever; although the patient has recovered and seems well as ever, there is a certain impairment of strength of which he is thoroughly conscious, but cannot clearly define. Injuries to the body and severe organic disturbances terminating in recovery, may, months and years after, be followed by some grave disease, which the patient obscurely traces back to these causes. Sunstroke, the action of poisons, or the profound impressions from fear, alarm, joy, or sorrow, leave entailments of degeneration which cannot be described, but nevertheless exist, as conditions of soil favorable for the growth of disease.

In these cases there is something wanting, and hints of changes which, like switches on the railway, indicate the point of departure from the main line. Along this field will frequently be found cases of inebriety that can be traced to some disease occurring long before. For instance, a severe attack of scarlatina, typhoid, malarious fever, or other disease, will recover with some condition of exhaustion and debility, that will remain and be followed years after by inebriety.

While the connection between these diseases and inebriety cannot be clearly traced from our present knowledge, yet there are many reasons for believing that such a 
chain exists. The first use of alcohol will be for its sedative effects, and although the reason and taste may repel its use, the impulse for it will always triumph. The various neuralgias seem to especially prepare the way for inebriety, and many forms of alcohol are ofter found almost specifics to lessen the pain of this affection. There is undoubtedly a very intimate connection between nutritive disturbances and inebriety. Dyspepsia very often precedes its outbreak; and the extensive use of bitters, whose chief substance is alcohol, depends largely upon this fact. For this reason, bitters or some lighter drinks are often called the causes of inebriety, when in reality they only serve to explode combinations of causes which may have been gathering through several generations. Along this same line may be classed all the perversions, the mental and physical dyspepsias from injurious education, etc. The varied combinations of bad influences in the early training of children, by which the natural harmony of growth is broken up, resulting in angular and imperfect development, is often the fertile soil for inebriety as well as insanity. Ambition that becomes an absorbing passion, filling every moment of thought, is attended with weakened nutritive functions which may react speedily in inebriety. There are a large class of men who are living constantly on the very brink of insanity and inebriety. They are always the centres of excitement and irregularities, of mental and physical health. The capricious appetites and thirst for different fluids, the free use of patent medicines, and many other symptoms, clearly forecast both inebriety and insanity. Some slight change and they are victims of these diseases at once. Inebriety, like many other diseases, will be found more prevalent at certain periods of life, which may be called more dangerous than others. No doubt certain physiological eras have a direct pathological influence over the nervous and nutrient system. In in- 
ebriety the period of puberty is full of danger. Prolonged excitement or intoxication after or during the first intercourse, is frequently the starting point of inebriety which may not break out for some time after. Dr. Mason found, in the statistics of two hundred and fifty cases, that inebriety appeared most frequently from fifteen to twenty-five, and from thirty to thirty-five.

Surroundings have a potent influence to either check or encourage inebriety. Among these may be mentioned, as active in the causation, mental states associated with a monotonous treadmill range of thought over and over again, that give no time for change or rest, notable among farmers, light-house keepers, men on the frontier, and workmen confined to the same special circle, etc.; in the other extreme, where the brain is never at rest, from the continuous change and strain to accommodate itself to the ever-shifting scenes that appeal to the reason and emotional faculties. Both are alike dangerous in their influence. Social surroundings enter largely into the early stages of inebriety. Physical surroundings have been recognized in the causation. Of these, high degrees of heat and cold are prominent, and are supposed to impair the nutrition of the nerves to such an extent as to produce paresis of the vaso-motor centres, bringing on inebriety.

It is found that firemen exposed to great heat soon become inebriates, particularly when employed on steamers that ply between northern and southern ports, where the extremes of temperature alternate in rapid succession. When inebriety has begun, a marked influence has been noted in many cases from the mountain or sea air. Some very remarkable instances have been stated of persons who had impulsive cravings for drink on the sea-shore, but in the interior these pass away, and complete self-control can be exercised. It is a common observation in every inebriate 
asylum, that.recently admitted patients seem very susceptible to all changes of the atmosphere. The danger of relapse is always greater at these times, showing a wide field of causes yet to be studied. Certain kinds of labor are thought to be prominent factors in the causation, especially night work, and labor in damp cellars excluded from the sun and proper air. Certain districts of this country and Europe are known to develop pauperism and inebriety in excess of all other sections. Here it may be called indigenous. These are only some of the general line of causes out of which inebriety and insanity spring. Inebriety is undoubtedly associated either as a symptom or cause of insanity, in many instances, but in a large proportion of cases it stands out alone as a distinct disease. The causes and conditions which govern its march, the pathology, symptomatology, and treatment, must be studied from the physical side to be understood.

From such study the obscure phenomena of periodicity, seen in many cases, will be made plain. The return of the desire for spirits after an interval, can often be predicted with great certainty. This drink-craving appears to move in regular cycles, which may be calculated within an hour. In one case this period was forty-one days and eight or ten hours, and never varied through a long course of years. In another this cycle is complete in one hundred and four or five hours, never varying under any circumstances or conditions. The interval was one of perfect freedom from spirits up to the hour of the returning influence.

The insane-like madness which characterizes inebriates, ignoring every thing but the impulse to procure spirits; and the precipitate revolution of character and motive, which passes swiftly from one extreme to another; and the sudden explosion of the diseased impulses into inebriety under ad- 
verse conditions,--all point significantly to disease under control of forces, whose movements are as certain as the march of the planets.

A noted violin-player was urged to take spirits for a nervous feeling before going on the stage, to allay this state and give brilliancy to his execution. He refused on the ground that, although it would steady his.nerves and quicken his execution, he would after a time blurr his notes, and, worse than all, he would never realize it.

This aptly expresses the strange delusion seen in all in ebriates, who never comprehend their words or actions, or the consequences of them. Alcohol seems not only to produce but intensify a form of moral paralysis, in which the consciousness of right and wrong is suspended, as well as a delusion of perfect control over all the actions of mind and body. This strange psychical condition is frequently limited to this special disease. On all other matters the reason and action will be unimpaired, but in the later stages the organism takes on profound degeneration. This strange blunting of the consciouness of right and wrong, and accurate conception of their own condition, is anomalous and not noticed in other diseases. The inebriate who from the lecture-stand recites, with vivid details, his own danger and condition, never carries it out practically. $\mathrm{He}$ is keenly alive to the conditions of others, but his own case is always an exception to the rule, in his opinion. M. Moreau wrote of the insane:

"It is only by incessant personal observation of such cases by day and by night, by watching their most trifling acts and prying into their thoughts, by inquiry of those around them, especially of their companions, toward whom they act freely and naturally, by identifying one's self, so to speak, with them, that we can succeed in obtaining an exact idea of their mental state, and comprehending to what extent their thoughts, desires, will, and actions are con- 
trolled by an irresistible, fatal, automatic influence in spite of the specious appearance which covers them with a false varnish of reason, moral liberty, and all the essential attributes of a man truly wortliy of the name."

This is literally true of the inebriate. In addition, his entire life must be studied, and all the evidence of heredity carefully examined; also, all the circumstances of his mental, physical, social, and sexual life considered as bearing on the disease. From these facts the questions of prognosis and treatment may be ascertained. What is needed to-day is accurate clinical, physiological study of inebriety, above the level of dogmatic assumption and speculative theory. Dr. Bellows wrote as follows:

"Inebriates, like the criminals and insane, will all be eventually restrained in hospitals and treated with medical and psychological skill the moment their liberty becomes dangerous to society. The terms of their confinement will be limited only by the possibilities of care and the conditions of their disorder. Society gains nothing by holding prisoner for an hour any man who is fit to be at large. Liberty and human rights gain nothing by allowing any man to be at large for a moment who is destroying himself, his family, and his neighbors. What we need is what we are fast gaining, namely, a possession of the. tests and gauges of this fitness or unfitness, and we shall be able to treat the inebriate successfully, the same as in other disease."

This very general review of the facts and conditions which the future study of inebriety will make clear, only faintly outlines a vast realm of truth now practically unknown,-a realm occupied by squatter frontiersmen and nonexperts, who will some day vanish before the settlements of truth and a knowledge of the laws and forces which govern this disease. 